\title{
Urinary excretion of 5-oxoproline (pyroglutamic aciduria) as an index of glycine insufficiency in normal man
}

\author{
By ALAN A. JACKSON*, A. V. BADALOO, T. FORRESTER, \\ J. M. HIBBERT AND C. PERSAUD* \\ Tropical Metabolism Research Unit, University of the West Indies, Mona, \\ Kingston 7, Jamaica
}

(Received 22 September 1986 - Accepted 20 May 1987)

\begin{abstract}
1. The evidence is accumulating to suggest that glycine, the simplest amino acid, is conditionally essential in man. Benzoic acid, by conjugation with glycine to form hippuric acid, is known to deplete the free glycine pool of the body. Glycine is one substrate for the enzyme glutathione synthase $(E C$ 6.3.2.3) and in the inborn error of metabolism in which glutathione synthase function is defective, increased quantities of 5-oxoproline are excreted in the urine.

2. An oral dose of 4-10 g sodium benzoate was given to six normal adults to deplete the metabolic pool of glycine, and the urinary excretion of 5-oxoproline was followed for $6 \mathrm{~h}$. In five of the six, a significant increase in the urinary 5-oxoproline was seen within $3 \mathrm{~h}$.

3. These findings show that 5-oxoprolinuria can result from limited glycine availability, and may provide a useful test for assessing glycine sufficiency in a range of physiological and pathological states.
\end{abstract}

In human nutrition, glycine has generally been considered to be a nutritionally dispensable (non-essential) amino acid (Rose, 1957). There is an absolute requirement for dietary glycine in the chick, apparently to satisfy the demands of uric acid synthesis (Almquist $e t$ al. 1940). Moreover, when the rat is faced with either the physiological stress of growth (Griffith, 1929), or the pathological stress of injury or trauma (Sitren \& Fisher, 1977), there is a narrow margin between the metabolic demand for glycine and the rate at which glycine can be formed or made available in the body. A marginal state of glycine availability is probably more common than has been appreciated in the past (Jackson, 1983). Recently, we presented evidence to show that glycine might behave as a conditionally essential amino acid in the preterm human infant (Jackson et al. 1981; Catzeflis et al.1985). Furthermore, Yu et al. (1985) have shown that in normal adults on a low-protein diet, glycine production in the body is insufficient to satisfy the normal metabolic demand. These findings suggest that glycine insufficiency might occur far more frequently, and be far more widespread than had been recognized (Christensen, 1986). It was for this reason that we had been looking for an index of glycine sufficiency in humans, that would be relatively simple to use in a range of clinical situations. The measurement of 5-oxoproline (5OP), L-pyroglutamic acid, in urine possibly represents just such an index. In a range of physiological and pathological conditions in which we had predicted an excessive demand for glycine, we were able to demonstrate increased urinary excretion of 5OP (Jackson et al. 1986).

5OP is a normal intermediate of the $\gamma$-glutamyl cycle (Meister, 1983) and may be detected at low levels in the urine of healthy individuals. Excessive loss of 5OP in the urine, 5oxoprolinuria (5OPuria), may be found in inborn errors of metabolism associated with either an increased production (glutathione synthase $(E C 6.3 .2 .3)$ deficiency) or decreased utilization (5-oxoprolinase deficiency) of 5OP by the body (Meister, 1978). In addition, increased urinary excretion of 5OP has been described in a range of pathological conditions,

* Present address: Department of Human Nutrition, University of Southampton, Bassett Crescent East, Southampton SO9 3TU. 


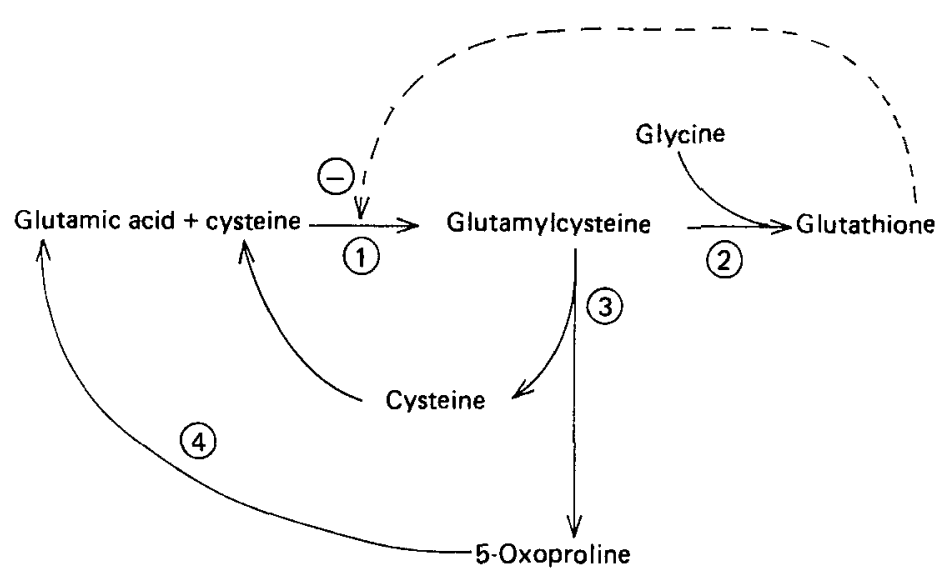

Fig. 1. Glutathione, $\gamma$-glutamylcysteinylglycine, is synthesized in two steps catalysed by glutamatecysteine ligase ( $\gamma$-glutamylcysteine synthetase) (EC 6.3.2.2), enzyme 1 , and glutathione synthase (EC 6.3.2.3), enzyme 2. Glutathione exerts feedback inhibition on enzyme 1 so that in the congenital absence of enzyme 2 excess $\gamma$-glutamylcysteine is cleaved by $\gamma$-glutamyl cyclotransferase (EC 2.3.2.4), enzyme 3, to give 5-oxoproline, which can be converted to glutamic acid by 5-oxoprolinase, enzyme 4 .

not known to be specifically associated with deficiencies of these enzymes (Larsson et al. 1983).

The mechanism whereby 5OPuria is produced is related to the control of glutathione synthesis, itself. Normally glutathione exerts control over its own rate of formation through feedback inhibition of the enzyme glutamate-cysteine ligase ( $\gamma$-glutamylcysteine synthetase (EC 6.3.2.2)) (Fig. 1). When the level of glutathione is reduced through a congenital absence of glutathione synthase, there is de-inhibition of glutamate-cysteine ligase, increasing the flow through this enzyme. As the normal pathway of utilization of $\gamma$ glutamylcysteine is blocked by a deficiency of the next enzyme, glutathione synthase, flow increases through the alternative pathway, $\gamma$-glutamyl cyclotransferase (EC 2.3.2.4), resulting in excessive production of 5OP. The capacity of 5-oxoprolinase to convert 5OP to glutamic acid is exceeded, leading to accumulation of 5OP and overflow into the urine, 5 OPuria. We reasoned that if glycine, one of the substrates for the glutathione synthase enzyme, were of limited availability, then the reduced rate of glutathione production might evoke a similar consequence as congenital absence of the enzyme glutathione synthase, resulting in 50Puria.

It has been recognized for many years that benzoic acid is cleared from the body as hippuric acid, following conjugation with glycine. Furthermore, when increasing loads of benzoic acid are given, a maximal rate of hippuric acid excretion is reached which is thought to be determined by the availability of glycine (Quick, 1931). In the present study we have used sodium benzoate, given orally, to create a drain on the available glycine pool in the body, so as to assess the ability of the body to mobilize endogenous glycine, and the effect that glycine would have on 5OP excretion in urine.

\section{METHODS \\ Experimental procedures}

Six healthy adults, three males and three females, were studied on three separate days each, following an overnight fast. A baseline urine was collected, followed by collection every $2 \mathrm{~h}$ for $6 \mathrm{~h}$. Every $2 \mathrm{~h}, 15 \mathrm{~g}$ sucrose were taken in $200 \mathrm{ml}$ fluid, thereby providing sufficient 
Table 1. The characteristics of the six subjects to show those who responded $(R)$ or did not respond $(N / R)$ to the ingestion of $4 \mathrm{~g}$ sodium benzoate by increasing the urinary excretion of 5-oxoproline in urine

\begin{tabular}{|c|c|c|c|c|c|c|c|}
\hline $\begin{array}{c}\text { Subject } \\
\text { no. }\end{array}$ & & $\begin{array}{c}\text { Age } \\
\text { (years) }\end{array}$ & $\begin{array}{r}W t \\
(\mathrm{~kg})\end{array}$ & $\begin{array}{l}\text { Height } \\
\text { (m) }\end{array}$ & $\begin{array}{l}\mathrm{Wt} / \mathrm{Ht}^{2} \\
\left(\mathrm{~kg} / \mathrm{m}^{2}\right)\end{array}$ & $\begin{array}{c}\text { Urinary } \\
\text { creatinine } \\
(\mu \text { mol } / \mathrm{kg} \text { per } 2 \mathrm{~h})\end{array}$ & Response \\
\hline 1 & $q$ & 27 & 63 & 1.65 & 23 & 13 & $\bar{N} / \mathbf{R}$ \\
\hline 2 & $\dot{q}$ & 30 & 51 & 1.56 & 21 & 18 & R \\
\hline 3 & $q$ & 31 & 48 & 1.61 & 19 & 12 & $\mathrm{R}$ \\
\hline 4 & $0^{*}$ & 21 & 71 & 1.79 & 22 & 16 & $\mathbf{N} / \mathbf{R}$ \\
\hline 5 & 0 & 34 & 86 & 1.84 & 26 & 22 & $\mathbf{N} / \mathbf{R}$ \\
\hline 6 & 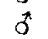 & 39 & 72 & 1.62 & 27 & 18 & $\mathrm{R}$ \\
\hline
\end{tabular}

energy to cover the expected expenditure and to ensure that a fed, 'anabolic' state was maintained. On the first study day, baseline excretion was measured in the timed urine specimens. On the second study day, each subject ingested sodium benzoate, $27.8 \mathrm{mmol}$, $4 \mathrm{~g}$ in $200 \mathrm{ml}$ water, immediately after passing the initial specimen of urine, and then proceeded as on the $1 \mathrm{st}$ day. On the $3 \mathrm{rd}$ day, $4 \mathrm{~g}$ sodium benzoate were ingested in a similar way, along with an approximately equimolar quantity of glycine, $2 \mathrm{~g}$.

\section{Analytical procedures}

The volume of urine was measured and a portion preserved in $200 \mu \mathrm{l} 6 \mathrm{M}$-hydrochloric acid. 5OP in urine was measured by the approach of Macpherson \& Slater (1959). Urine, $2 \mathrm{ml}$, was deproteinized with an equal volume of perchloric acid $(10 \mathrm{ml} / 1)$. Following centrifugation, $10 \mathrm{~min}$ at $3500 \mathrm{rev} / \mathrm{min}, 1 \mathrm{ml}$ of supernatant fraction was diluted with $4 \mathrm{ml}$ water and $2 \mathrm{ml}$ of this solution was added to $2 \mathrm{ml} 6 \mathrm{M}-\mathrm{HCl}$ and heated at $100^{\circ}$ for $3 \mathrm{~h}$. The solution was heated to dryness and the residue reconstituted with $2 \mathrm{ml}$ distilled water. Glutamic acid was determined in $200 \mu \mathrm{l}$ of the treated (acid hydrolysed) and untreated sample using glutamate dehydrogenase (EC 1.4.1.2) (Sigma Chemical Co., Poole, Dorset) by the method of Bernt and Bergmeyer (Bergmeyer, 1974) with a Tris in hydrazine buffer. Acid hydrolysis of the urine converts 5OP to glutamic acid. Therefore the 5OP excretion was calculated as the difference between the measured glutamic acid in the treated and untreated samples. Creatinine in urine was measured by the alkaline picrate method of Jaffe (Bonsnes \& Taussky, 1945), after pretreatment of the urine with Lloyd's reagent to remove interfering chromogens. The excretion of 5OP was expressed as a ratio, relative to the excretion of creatinine, an expression that had been found in preliminary studies to be the same for both sexes at all times of the day. Hippuric acid in urine was measured by the method of Wilczok \& Bieniek (1978).

\section{RESULTS}

The age, weight and height of the experimental subjects are shown in Table 1. The oral sodium benzoate was tolerated by the subjects although all experienced varying degrees of nausea, bloating or epigastric discomfort. There was no consistent or significant variation in creatinine excretion from study to study for any one individual (Table 1), and the interpretation of the 5OP excretion values was the same whether the results were expressed as a ratio, absolute rates, or relative to the individual baseline excretion for that particular day. 


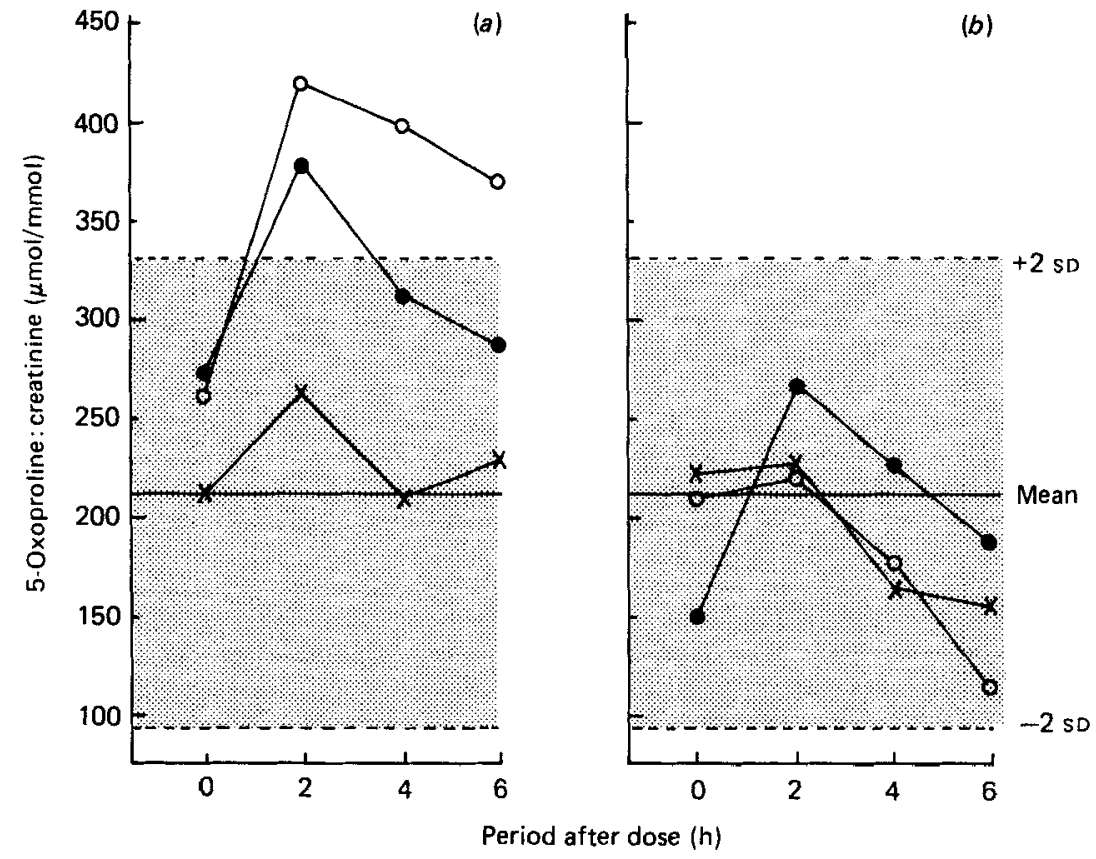

Fig. 2. The basal excretion of 5-oxoproline $(x-x)$ was increased significantly in three subjects. $(a)$ following the ingestion of $4 \mathrm{~g}$ sodium benzoate $\left(\mathrm{O}_{-}-\mathrm{O}\right)$, with a reduced response when $2 \mathrm{~g}$ glycine was taken with the benzoate (-O). Three subjects $(b)$ failed to respond and 5-oxoproline excretion remained within the normal range.

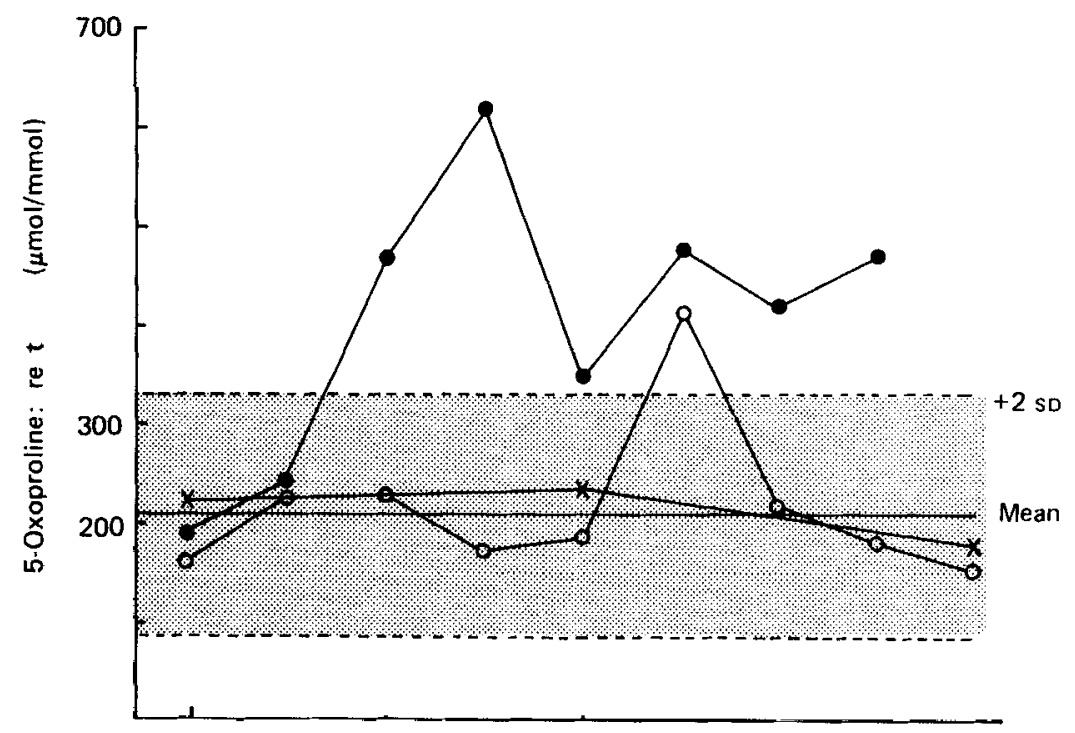

Period after dose $(\mathrm{h})$

Fig. 3. In two of the three subjects who failed to show a response to $4 \mathrm{~g}$ sodium benzoate, a significant increase was seen following the ingestion of $10 \mathrm{~g}$ benzoate in subjects nos $4(-)$ ) and $5(\mathrm{O}-\mathrm{O})$. 


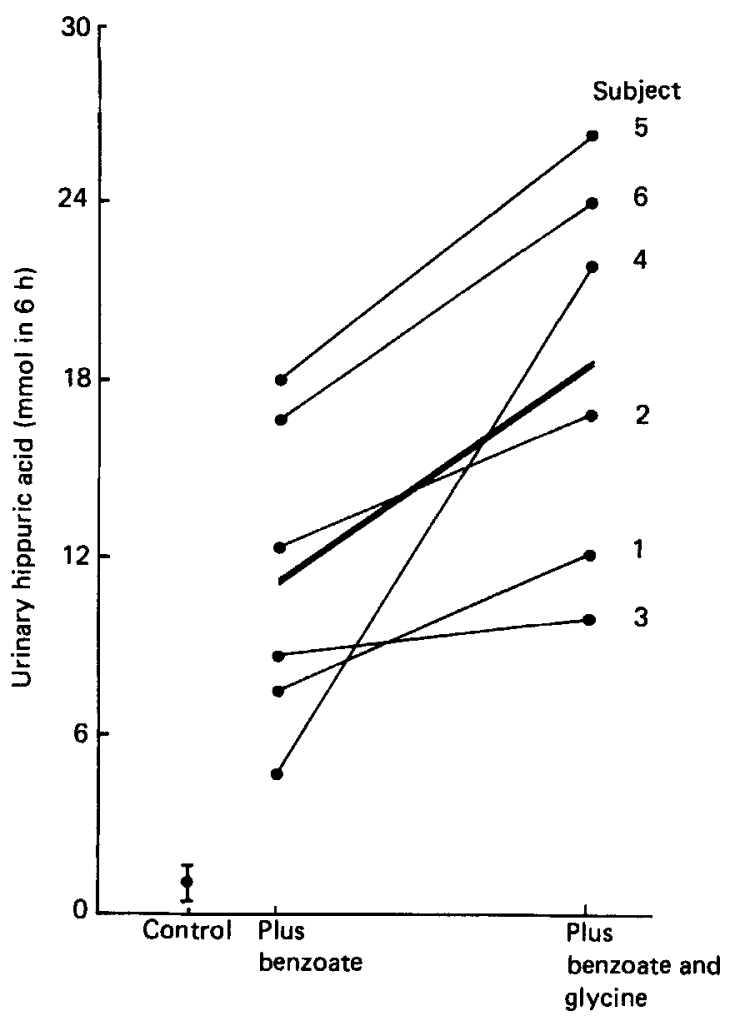

Fig. 4. The excretion of hippuric acid in urine over the $6 \mathrm{~h}$ of study on the control day (mean value and standard deviation represented by vertical bars) compared with the excretion of hippuric acid in the $6 \mathrm{~h}$ following the ingestion of $4 \mathrm{~g}$ sodium benzoate, or $4 \mathrm{~g}$ sodium benzoate with $2 \mathrm{~g}$ glycine.

For all specimens collected on study day 1 , the ratio, 5OP: creatinine $(\mu \mathrm{mol} / \mathrm{mmol})$ was 210 (SD 60; $n$ 24). This gave an upper limit to the normal range $+2 \mathrm{sD}$, of 330 (Fig. 2). It was possible to divide the subjects into two distinct groups with respect to their response to the load of sodium benzoate. Three subjects showed a positive response, in that there was a significant increase in the excretion of 5OP to more than twice normal, within the first $2 \mathrm{~h}$ after the ingestion of sodium benzoate (Fig. 2). This response was reduced but not abolished when glycine was given with the sodium benzoate. In the other three subjects there was no obvious change in urinary $50 \mathrm{OP}$ in response to sodium benzoate either without or with additional glycine. Each subject received a fixed dose of sodium benzoate, a quantity estimated to be sufficient to provoke a significant drain on the glycine pool. It was considered possible that in the three subjects who did not show a response, the $4 \mathrm{~g}$ sodium benzoate might have been insufficient to produce glycine privation. Therefore, in two of the non-responding subjects the study was repeated with a larger dose, $10 \mathrm{~g}$ sodium benzoate. The response to the $10 \mathrm{~g}$ is shown in Fig. 3. For each subject there was an increased excretion of 5OP within $3 \mathrm{~h}$ of the ingestion of the larger dose, with a much more marked response in subject no. 4 than in subject no. 5. This confirmed that in normal adults 5OPuria could be provoked if sufficient sodium benzoate were given to provide an effective drain on the available glycine pool. The baseline excretion of hippuric acid in urine, 0.18 (SD 0.10$) \mathrm{mmol} / \mathrm{h}$, increased following the administration of sodium benzoate to 1.89 (SD $0.88) \mathrm{mmol} / \mathrm{h}$. The excretion of hippuric acid increased further to $3 \cdot 11$ (SD $1 \cdot 11) \mathrm{mmol} / \mathrm{h}$ 
when equimolar quantities of glycine were taken with the sodium benzoate, providing confirmatory evidence that hippurate formation and excretion was limited by the availability of glycine (Fig. 4) (Quick, 1931). In all subjects the excretion of hippuric acid had returned to baseline levels by $6 \mathrm{~h}$. In the three responders maximal hippuric acid excretion was seen during the second $2 \mathrm{~h}$ period when supplemental glycine was not given, and during the first $2 \mathrm{~h}$ period with supplemental glycine. In the three non-responders the peak excretion of hippuric acid was during the first $2 \mathrm{~h}$ period both without and with the supplemental glycine.

\section{DISCUSSION}

Although glycine is the simplest amino acid, with only two carbon atoms, neither of which is asymmetrical, our understanding of its origin and formation in the body is fragmentary (Arnstein, 1954). In contrast we have a far more detailed appreciation of the important role played by the glycine molecule in a range of specific synthetic reactions that are central to metabolism, e.g. prophyrins, glutathione, nucleotides, bile salts, creatine, etc. Therefore, it is to be expected that any disturbance in metabolism that caused an impairment of glycine formation or availability would have a widespread influence on metabolism generally, and intermediary metabolism in particular.

The efficiency with which the body is able to clear an oral or intravenous load of benzoic acid, by conjugation and excretion as hippuric acid, has been used in the past as a test of hepatic function (Quick, 1931). There is an upper limit to the rate at which hippuric acid can be formed and excreted. As the rate-limiting step is conjugation of benzoic acid with glycine, the metabolic availability of glycine is probably of greater importance than any other aspect of hepatic function or renal clearance in determining the rate of clearance of benzoic acid. In the present study we have shown that there may be demonstrable consequences to the depletion of the metabolic pool of glycine. By diverting glycine to hippuric acid synthesis and away from glutathione synthesis we were able to produce an increase in the urinary excretion of 5OP in three of six subjects taking $4 \mathrm{~g}$ sodium benzoate, and in a further two when the dose was increased to $10 \mathrm{~g}$. The variation in response between subjects is probably related to the different efficiency with which glycine can be mobilized for metabolic interaction. In the three non-responders, urinary hippurate excretion was prompt following the ingestion of sodium benzoate, whereas in the three responders maximal hippurate excretion was delayed until the second $2 \mathrm{~h}$ period.

We had previously shown that in states where the demand for glycine is very high, such as pregnancy and sickle-cell disease, the urinary excretion of 5OP was significantly increased, as predicted (Jackson et al. 1986). As we have been able to induce a similar response by the specific depletion of glycine with benzoic acid, this argues strongly in favour of 5OPuria being a useful index of the metabolic availability of glycine. The further implication of these observations would be that the production and availability of glutathione is sensistive to glycine status and may be less than optimal under circumstances of limited glycine availability.

During the third study an equimolar quantity of glycine was given to provide ample for the formation of hippuric acid. Although hippuric acid excretion was increased, the 5OPuria was not corrected completely. This observation is in keeping with the findings of earlier work, which shows that the metabolic compartmentation of glycine and benzoic acid is different (Simkin \& White, 1957). Thus glyoxylic acid, which forms glycine by transamination in the liver, may be far more efficient than glycine itself, for the formation of hippuric acid, presumably because glyoxylic acid forms glycine at a site close to where the hippuric acid is synthesized (Weinhouse \& Friedmann, 1951).

Sodium benzoate (4-10 g) produced a transient increase in 5OP excretion lasting a few 
hours at the most. Therefore it is reasonable to conclude that in physiological or pathological states in which there is a persistent, prolonged increase in 5OP excretion, the drain on the available glycine pool is likely to be functionally significant. Thus in sickle-cell disease the ongoing haemolysis creates a demand for glycine of the order of $1-2 \mathrm{~g} / \mathrm{d}$ to satisfy the needs of haem synthesis. A normal dietary intake might just provide this amount of glycine, and endogenous synthesis of glycine ( $\mathrm{Yu}$ et al. 1985) must be insufficient to satisfy the remaining needs of the body (Jackson, 1984). Hence the finding of 5OP in patients with sickle-cell disease indicates that these people exist in a chronically precarious state with respect to glycine sufficiency. Similar difficulties may be seen during periods of intense growth. The demands of the growing fetus for glycine are very high, in both absolute terms, and relative to other amino acids, two to ten times as great on a molar basis (Widdowson et al. 1979). Therefore it is not surprising to find that as early as the 12th week of gestation the urinary 5OP is increased, and the increase becomes progressively more marked as pregnancy advances, to reach very high levels just before term (Jackson et al. 1986).

Benzoic acid, and other related compounds that form hippuric acid, are found in relatively high concentrations in some fruits, e.g. prunes or cranberries. Benzoic acid is used widely in the food industry as a preservative. Under normal circumstances these sources of benzoic acid can be handled with ease at the levels found in the total diet by most normal individuals. However, even these low levels might present a problem to individuals who already have a compromised glycine status in trying to satisfy an increased demand, e.g. pregnancy or sickle-cell disease. Increasingly, anecdotal reports of the adverse effects of a range of food additives has caught the imagination of the general public. It may be worthy of note that one of the earliest descriptions of 5OPuria was in subjects with allergic disease (Tham et al. 1968). Young rats treated chronically with sodium benzoate failed to grow normally, became restless, irritable and developed abnormal movements. When housed in groups these animals became very vicious and fighting occurred at frequent intervals (Griffith, 1929).

Large doses of benzoic acid have been used therapeutically to treat inborn errors of the urea cycle enzymes, and the evidence is that considerable benefit can be conferred by providing an alternative route for nitrogen excretion (Batshaw et al. 1982). In young experimental animals treated chronically with benzoate, the marked growth failure may be ameliorated by giving supplemental glyoxylic acid, but the safe therapeutic range is very narrow (White, 1941; Weissbach \& Sprinson, 1953).

A possible alternative explanation for our findings might be that benzoic acid itself, or hippuric acid, acts directly on some other aspect of 5OP metabolism. Although unlikely, this possibility has not been directly ruled out as yet. Certainly the evidence presented here, and the wide implications that it carries for our understanding of the role played by the metabolism of non-essential amino acids in health and disease, justifies further in-depth investigation.

The support of the Wellcome Trust is gratefully acknowledged.

\section{REFERENCES}

Almquist, H. J., Stokestad, E. L. R., Mecchi, E. \& Manning, P. V. D. (1940). Journal of Biological Chemistry 134, 213-216.

Arnstein, H. R. V. (1954). Advances in Protein Chemistry 9, 1-91.

Batshaw, M. L., Brusilow, S., Waber, L., Blom, W., Brubakk, A. M., Burton, B., Cann, H., Kerr, D., Mamunes, P., Myerberg, D. \& Schafer, I. (1982). New England Journal of Medicine 306, 1387-1392.

Bergmeyer, H. U. (1974). Methods of Enzymic Analysis, vol. 3, pp. 1719-1722. New York: Verlag Chemie, Weinheim/Academic Press. 
Bonsnes, R. W. \& Taussky, H. H. (1945). Journal of Biological Chemistry 158, 581-591.

Catzeflis, C., Schutz, Y., Micheli, J.-L., Welsch, C., Arnaud, M. J. \& Jequier, E. (1985). Pediatric Research 19 , 679-687.

Christensen, H. N. (1986). Federation Proceedings 45, 2165-2166.

Griffith, W. H. (1929). Journal of Biological Chemistry 82, 415-427.

Jackson, A. A. (1983). Lancet i, 1034-1037.

Jackson, A. A. (1984). In Genetic Factors in Nutrition, pp. 297-315 [A. Velazquez and H. Bourges, editors]. New York: Academic Press.

Jackson, A. A., Persuad, C., McDermott, J. \& deBenoist, B. (1986). Proceedings of the Nutrition Society 45, 92A.

Jackson, A. A., Shaw, J. C. L., Barber, A. \& Golden, M. H. N. (1981). Pediatric Research 15, $1454-1461$.

Larsson, A., Mattsson, B., Wauters, E. A. K., van Gool, J. D., Duran, M. \& Wadman, S. K. (1983). In Functions of Glutathione: Biochemical, Physiological, Toxicological, and Clinical Aspects, pp. 325-336 [A. Larsson, S. Orrenius, A. Holmgren and B. Mannervik, editors]. New York: Raven Press.

Macpherson, H. T. \& Slater, J. S. (1959). Biochemical Journal 71, 654-660.

Meister, A. (1978). In The Metabolic Basis of Inherited Disease, pp. 328-335. [J. B. Stanbury, J. B. Wyngaarden and D. S. Fredrickson, editors]. New York: McGraw Hill Book Co.

Meister, A. (1983). In Functions of Glutathione: Biochemical, Physiological, Toxicological, and Clinical Aspects, pp. 1-22 [A. Larsson, S. Orrenius, A. Holmgren and B, Mannervik, editors]. New York: Raven Press.

Quick, A. J. (1931). Journal of Biological Chemistry 92, 65-85.

Reed, D. J. \& Fariss, M. W. (1984). Pharmacological Reviews 36, 25S-33S.

Rose, W. C. (1957). Nutrition Abstracts and Reviews 27, 631-647.

Simkin, J. L. \& White, K. (1957). Biochemical Journal 65, 574-582.

Sitren, H. S. \& Fisher, H. (1977). British Journal of Nutrition 37, 195-208.

Tham, R., Nystrom, L. \& Holmstedt, B. (1968). Biochemical Pharmacology 17, 1753-1758.

Weinhouse, S. \& Friedmann, B. (1951). Journal of Biological Chemistry 191, 707-717.

Weissbach, A. \& Sprinson, D. B. (1953). Journal of Biological Chemistry 203, 1023-1037.

White, A. (1941). Yale Journal of Biology and Medicine 13, 759-768.

Widdowson, E. M., Southgate, D. A. T. \& Hey, E. N. (1979). In Nutrition and Metabolism of the Fetus and Infant, pp. 169-177 [H. K. Visser, editor]. The Hague: Martinus Nighoff Publishers.

Wilczok, T. \& Bieniek, G. (1978). British Journal of Industrial Medicine 35, 330--334.

Yu, Y. M., Yang, R. D., Matthews, D. E., Wen, Z. M., Burke, J. F., Bier, D. M. \& Young, V. R. (1985). Journal of Nutrition 115, 399-410. 